Insight, part of a Special Feature on Restoring Riverine Landscapes

\title{
River Restoration and Meanders
}

\author{
G. Mathias Kondolf ${ }^{1}$
}

\begin{abstract}
Among the most visually striking river restoration projects are those that involve the creation of a new channel, often in a new alignment and generally with a form and dimensions that are different from those of the preproject channel. These channel reconstruction projects often have the objective of creating a stable, single-thread, meandering channel, even on rivers that were not historically meandering, on rivers whose sediment load and flow regime would not be consistent with such stable channels, or on already sinuous channels whose bends are not symmetrical. Such meandering channels are often specified by the Rosgen classification system, a popular restoration design approach. Although most projects of this type have not been subject to objective evaluation, completed postproject appraisals show that many of these projects failed within months or years of construction. Despite its, at best, mixed results, this classification and form-based approach continues to be popular because it is easy to apply, because it is accessible to those without formal training in fluvial geomorphology, and probably because it satisfies a deep-seated, although unrecognized, cultural preference for single-thread meandering channels. This preference is consistent with 18th-century English landscape theories, which held the serpentine form to be ideal and led to widespread construction of meandering channels on the country estates of the era. The preference for stability in restored channels seems to be widely accepted by practitioners and funders despite the fact that it is antithetical to research showing that dynamically migrating channels have the greatest ecological richness.
\end{abstract}

Key Words: river restoration; meandering channels; cultural preferences; channel classification

\section{INTRODUCTION}

River restoration has emerged as an increasingly important activity in North America and Europe to improve water quality, enhance aquatic and riparian habitat, and facilitate human uses (Downs et al. 2002, Bernhardt et al. 2005). Among the most visually striking types of river restoration worldwide are channel reconstructions: projects that involve the creation of a new channel, often in a new alignment and generally with a form and dimensions that are different from those of the preproject channel. Many channel reconstruction projects have the objective of creating a stable, single-thread, meandering channel. Recreating meanders is a reasonable and obvious goal on rivers whose historical bends were lost to channel straightening projects, as is well documented on many rivers and streams in Europe (e.g., Brookes 1987, Goldi 1991, Iversen et al. 1993). However, meanders have also been created in many channel reconstructions on rivers that were not historically meandering, and in some cases irregularly sinuous channels have been reconstructed into symmetrical meanders. In many cases, these meanders have subsequently washed out (Kondolf et al. 2001, Smith and Prestegaard 2005), and, even if they remain stable, they are unlikely to provide the habitat that would naturally exist at the site. If we take the perspective that alluvial channel form reflects the independent variables of flow and sediment load, we might expect that attempts to impose meanders on rivers in which they would not spontaneously occur would be futile, unless the bed and banks are heavily armored to prevent channel change, as on the 1997 West Walker River channel reconstruction in California. Irregularly sinuous rivers with low stream power and low sediment supply can often be converted to symmetrical meanders without washing out, but the ecological benefits of such conversions are questionable. The persistent popularity of meandering channel 
reconstructions raises questions about how channel reconstructions are designed and why.

The success rate of such reconstructed meandering channels is not known because there have been few objective studies to assess postproject performance. In part, reluctance to fund postproject appraisals may be related to challenges in setting performance criteria, such as difficulties in setting and measuring quantitative goals in the face of uncertainties in outcome. The lack of postproject appraisal is characteristic of river restoration as a whole, not only channel reconstruction (Kondolf and Micheli 1995, Bernhardt et al. 2005; www.nrrss.umd.edu), but in some respects is more remarkable for channel reconstruction projects given the inherently invasive and costly nature of the procedures. Funding for restoration projects is commonly for implementation only; there may be less motivation to fund postproject appraisals, perhaps in part because the evaluations may raise questions about project effectiveness. The unhappy results of this failure to adequately monitor and assess project performance include the repetition of mistakes and a lack of understanding of the larger effects of individual projects (Kondolf 1995a).

In this paper, I describe a dominant paradigm in river restoration today: the creation of a stable, single-thread, meandering channel, most often by reconstructing the channel based on a classification system. This paper reports on the actual performance of some examples of channel reconstruction projects in California, considers the ecological implications of attempting to force a channel to be stable, and explores possible cultural roots of what is evidently a widespread attraction to single-thread, meandering channels.

\section{THE CURRENT PARADIGM: RECONSTRUCTION TO A STABLE, SINGLE-THREAD, MEANDERING CHANNEL}

Probably the most widely accepted approach to river restoration is to construct a single-thread channel, a design based on the notion that, if the channel shape and dimensions are correct, the channel will be stable. In effect, this approach is the intellectual descendent of the regime canals built by British irrigation engineers in India, which neither eroded nor aggraded but efficiently carried the water and sediment in equilibrium (Leopold et al. 1964). In
North America, the most popular method for designing this ideal channel is the application of the Rosgen classification system (Rosgen 1994, Malakoff 2004). This method involves an inventory and classification of stream types according to the Rosgen classification system, the selection of structures to correct limitations based on suitability for stream types, and implementation (Rosgen and Fittante 1986). The projects so designed typically have the outsides of the meander bends stabilized with large boulders and the butt ends of trees, with the roots sticking out into the channel, and include boulder structures in the bed (Fig. 1). Until recently, the boulder structures were vortex rock weirs, i.e., lines of boulders crossing the stream in a $U$ shape, with the open part of the $U$ facing downstream (Rosgen 1996). More recently, these projects have tended to involve boulder lines that extend from the bank partway across the channel. Many of these restored channels were naturally composed of smaller alluvial sediment and would not have had boulders in them, which poses challenges for the evaluation of such projects.

Reliance on this classification system as a basis for restoration design has been widely criticized by scientifically trained geomorphologists (e.g., Kondolf 1995b, Miller and Ritter 1996, Doyle et al. 1999, Juracek and Fitzpatrick 2003). Nevertheless, this approach has proved remarkably popular with managers, decision makers, and biologists, probably because it promises to identify the stable geometry for the given conditions, it is easy to apply, and it makes the discipline of fluvial geomorphology seem comprehensible to those without scientific training in it. The Rosgen system has been adopted by numerous state, provincial, and federal agencies in North America (Malakoff 2004). The U.S. National Research Council did not explicitly endorse the Rosgen approach but termed its use "advisable" (NRC 1992). The NRC devoted more than nine pages of its 1992 report to presenting the method, including eight pages containing a detailed table specifying the sorts of structures to be installed for each "stream type" (NRC 1992:233-244). Although there is no definitive count of the channel reconstructions built based on this system, the number is large and growing, and it is probably fair to say that this approach is a reigning paradigm of river restoration in North America, although not in Europe or Australia.

A number of factors have probably contributed to the popularity of this approach to river restoration 
Fig. 1. Diagram of root wads and boulders to be installed in Cuneo Creek, California (from Rosgen 1991).

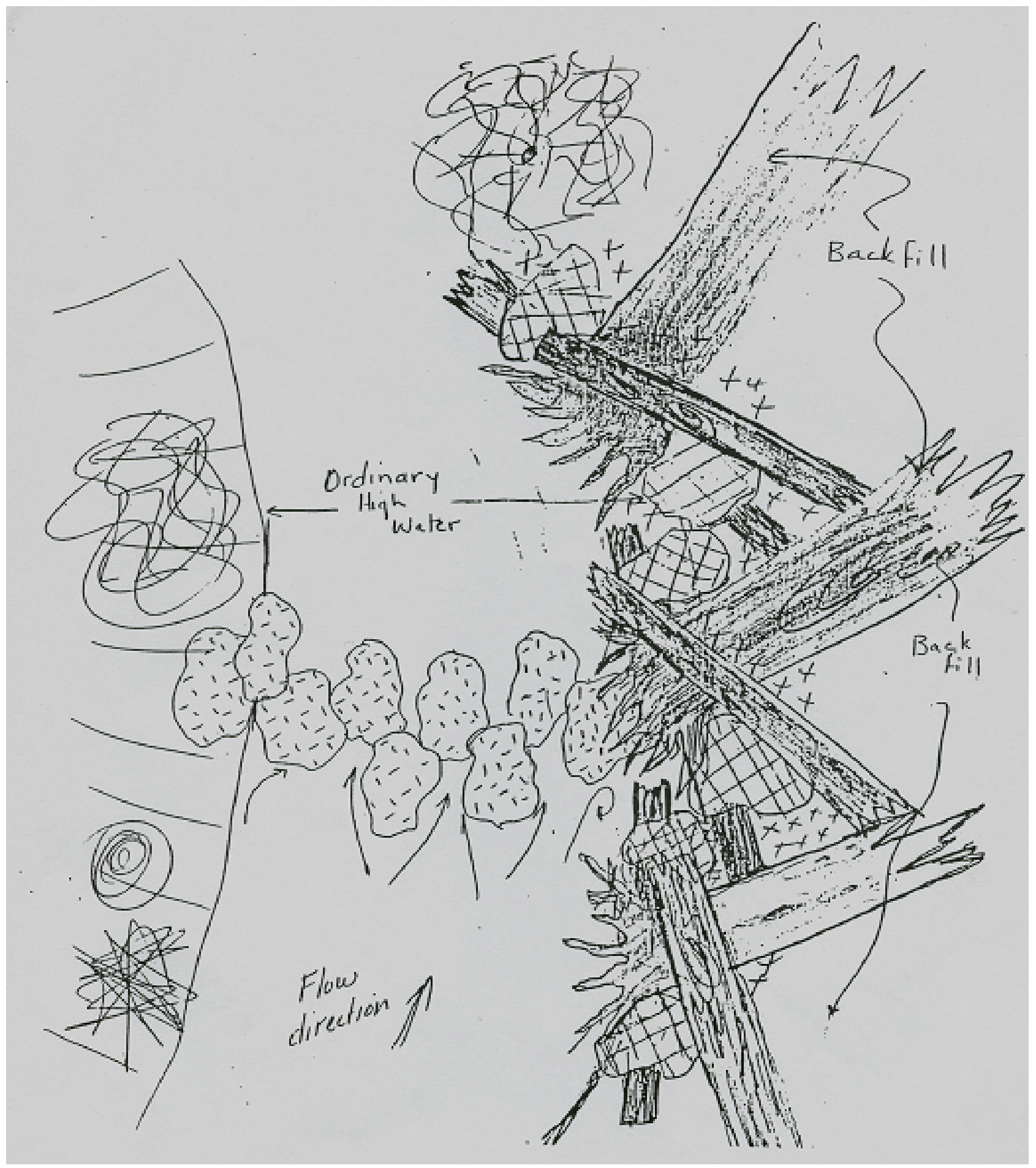


design. First, the classification scheme is accessible to people without academic training in fluvial geomorphology, by virtue of both the simplicity of the approach itself and the availability of week-long training courses taught by a charismatic instructor. Because of their ability to categorize channels based on their appearance, initiates into the system gain a sense of knowledge and understanding of rivers and feel empowered to undertake major alterations to river channels. Managers are attracted to the system because they can quickly train staff and begin undertaking projects without the long delays that a scientific study might entail. The classification system commonly predicts that a single-thread, meandering channel is the "proper" channel geometry for a given site, and that such a channel will be stable. Stability is often a goal of channel reconstruction projects, despite a body of scientific literature indicating that dynamic, actively migrating channels provide the best ecological habitats and that the ecological value diminishes with decreased flow and channel dynamics (e.g., Ward and Stanford 1995, Richards et al. 2002). Thus, a goal informed by geomorphic and ecological understanding might more appropriately be something like the following: the channel and its ecology should be self-created and dynamic over a time scale commensurate with the frequency of effective events. However, practitioners know how to build single-thread, meandering channels, and the specification of structures appropriate to different channel types (Rosgen and Fittante 1986) provides a step-by-step "cookbook" approach to restoration design.

\section{ILLUSTRATIVE CASE STUDIES}

The paradigm described above has been applied in rivers throughout North America, but the fate of most such projects has not been documented or the experiences widely disseminated. Even in humid Atlantic climates in which a bankfull-discharge approach to channel design might arguably have a better basis for applicability, the success of such projects has been mixed at best. Smith and Prestegaard (2005) documented the failure of a channel reconstruction on Deep Run, Maryland, following its conversion into a C3 channel. In the Coast Ranges of California, with its Mediterranean climate and episodic flow regime (Hecht 1994, Gasith and Resh 1999), we would expect infrequent events to exert a relatively greater influence on channel form (Wolman and Gerson 1978), which would make the applicability of the current paradigm even more questionable. This current form-based paradigm does not explicitly consider historical changes, physical and ecological processes, or variables that could be very relevant for classifying rivers but cannot be measured/ observed from channel form, such as sediment supply. Nonetheless, many such projects have been constructed, and many have failed. Two case studies illustrate the shortcomings of using the Rosgen classification system approach to design channel reconstructions.

\section{Cuneo Creek}

Cuneo Creek drains $10.8 \mathrm{~km}^{2}$ of the Coast Ranges, flowing into Bull Creek and thence the South Fork Eel River (Fig. 2). The basin is underlain by erodible sedimentary rocks of the Franciscan and Yager Formations, fractured and uplifted by active tectonics. The climate is Mediterranean, with highly seasonal winter rainfall, high interannual variability in precipitation, and consequently an episodic flow regime. The mostly Douglas-fir (Pseudotsuga

menziesii) forest of the basin was logged almost in its entirety in the 1950s and early 1960s. Intense storms in water years 1955 and 1965 (December 1964) produced massive hill-slope erosion and sediment delivery to the channel of Cuneo Creek, with aggradation of $5 \mathrm{~m}$ in 1955 and another $5 \mathrm{~m}$ in 1965 at Cuneo Creek's confluence with Bull Creek (Hansen 2003). Aggradation in Bull Creek downstream contributed to channel instability and bank erosion, which threatened old-growth redwoods in Humboldt Redwoods State Park. In the 1960s, the California Department of Parks and Recreation (Parks) purchased the deforested Cuneo Creek catchment to restore and reduce its sediment yield (Hansen 2003). However, the hill slopes continue to erode, with the still-active Devil's Elbow Slide threatening a county road (Short 1993). Reflecting this high sediment supply, the channel of Cuneo Creek is braided, with multiple threads shifting over an active channel bed of gravel and sand $150 \mathrm{~m}$ wide and with a slope of approximately 0.03 (Fig. 3).

In 1991, Parks reconstructed a 520-m reach of Cuneo Creek as a meandering C3 channel based on the application of the Rosgen classification system, with a constructed channel width of approximately $10 \mathrm{~m}$ (ranging from 6 to $14 \mathrm{~m}$ ) and a slope of 0.02 (Rosgen 1991). In 1997, the constructed channel 
Fig. 2. Location map, Cuneo Creek (from Short 1993).

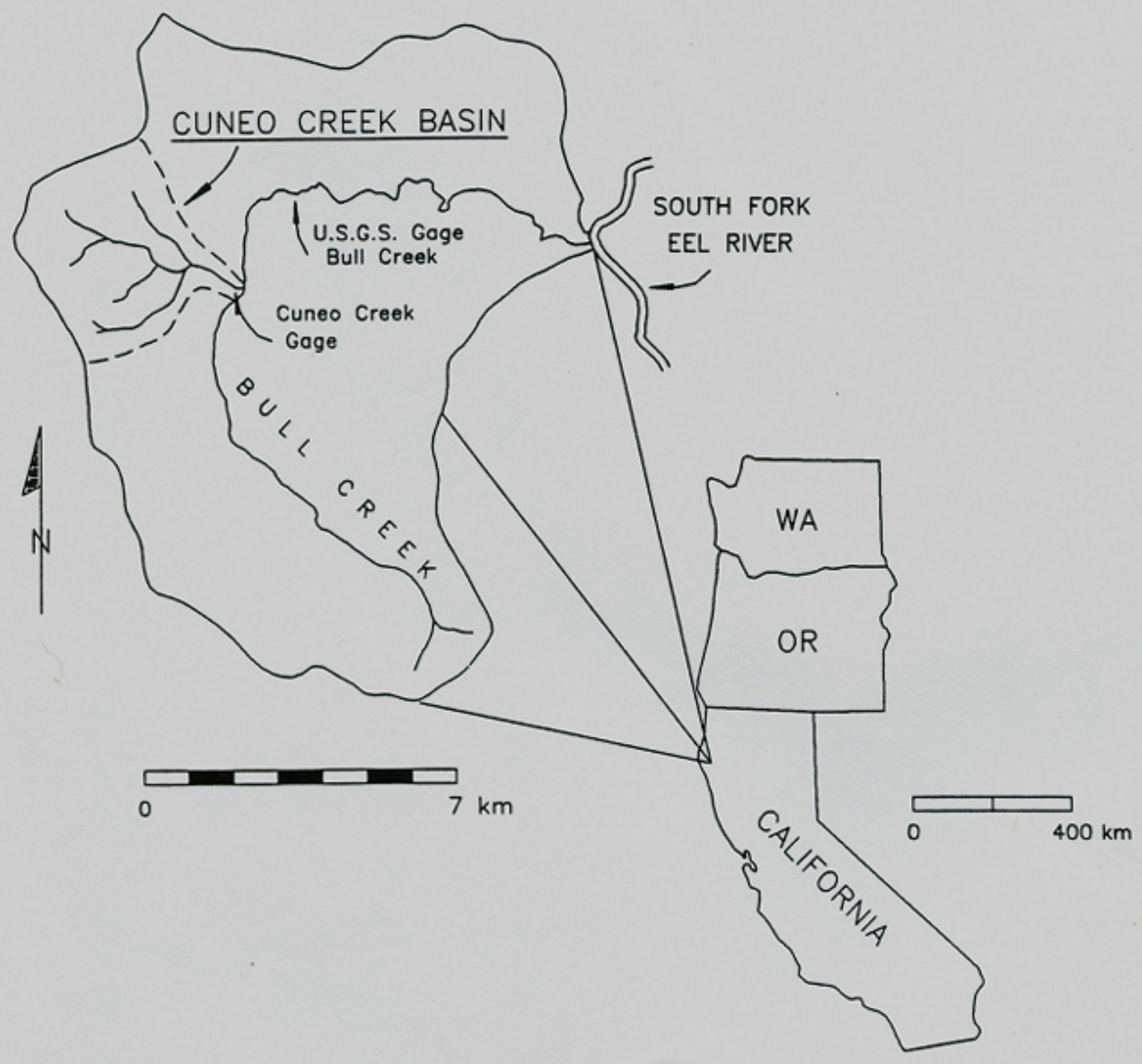


Fig. 3. Aerial photograph, Cuneo Creek (courtesy of the California Department of Parks and Recreation).

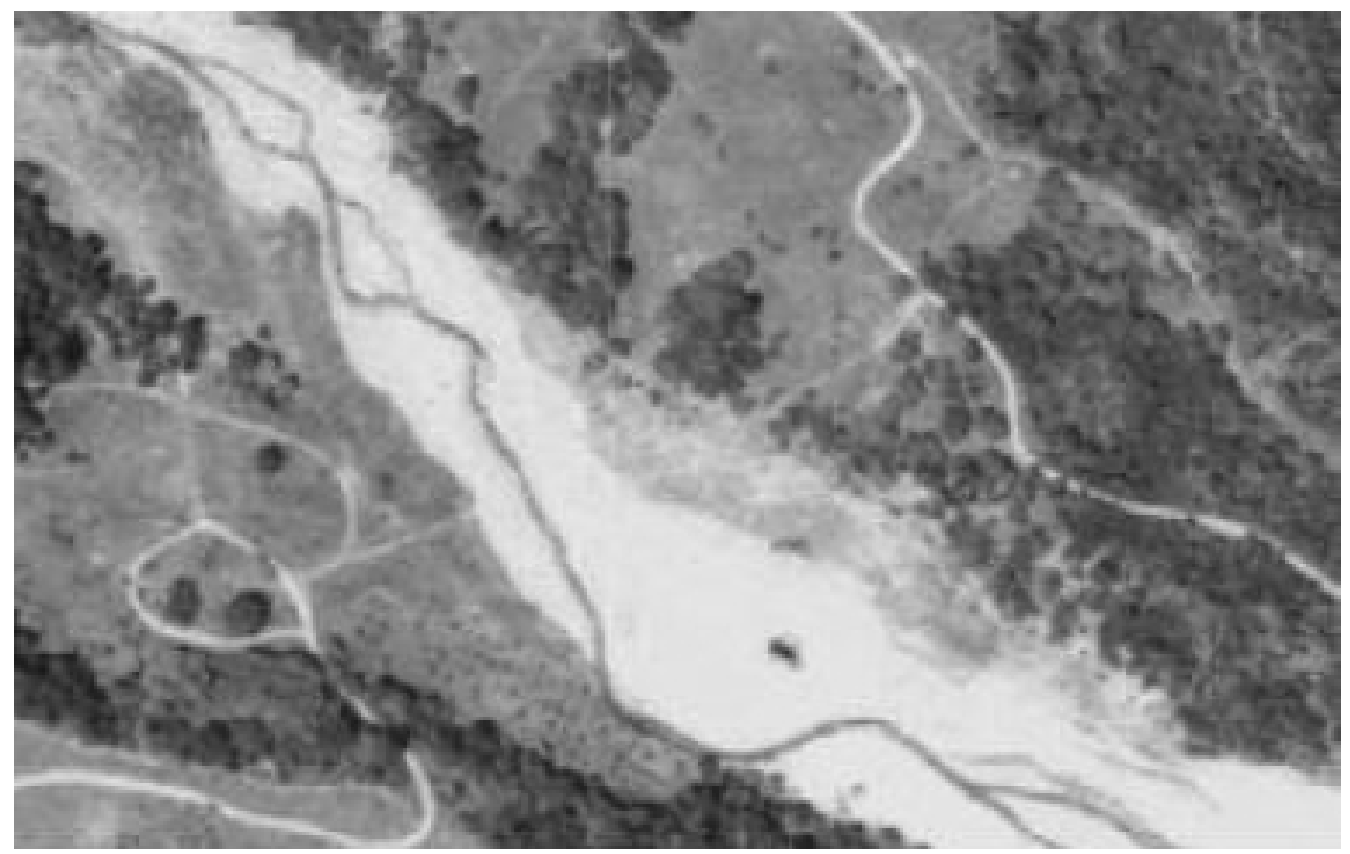

washed out in a flow with return interval of about $30 \mathrm{yr}$, leaving virtually no evidence in channel (Figs. 3 and 4). The consultant had originally proposed the reconstruction of a $1600-\mathrm{m}$ reach as a meandering C3 channel, with 43 meander bends (Rosgen 1991; Fig. 5). However, Parks reduced the scope of the project to minimize impacts on already improving habitat and to better transition from the wide, braided channel existing at the site to the reconstructed channel (Burson 1992). The consultant expressed concern about inconsistencies between the original design and the actual construction, arguing that design changes such as installing only one vortex rock weir per meander crossover instead of two would make the project less stable. However, in understanding why the Cuneo Creek project failed, it is instructive to step back from design details to consider the evolution of this project in the larger catchment context.

Geomorphic theory holds that alluvial channels reflect the flow and sediment load supplied to them, along with geologic controls, bank vegetation, and other influences. It is well documented in the literature that increasing the supply of bedload from the catchment can cause a channel to widen, and that decreasing bedload supply can cause narrowing (see Kondolf et al. 2002 for contrasting cases from Idaho and southern France). The preproject braided channel of Cuneo Creek reflected its high bedload supply and the episodic flow regime characteristic of the hydrology of the Mediterranean climate of the Coast Range. Thus, without reducing the enormous supply of coarse sediment coming from hill slopes to the channel, which would probably be a long-term, expensive effort, and without changing the episodic hydrology (unlikely), it is unclear how simply constructing a narrow, single-thread, meandering channel could be expected to change the character of Cuneo Creek in a sustainable way. When viewed from a scientific geomorphic perspective, it would matter little whether the crossovers were protected by one rock weir or two. The enormous sediment loads of Cuneo Creek, which were capable of burying the bridge on the county road under $5 \mathrm{~m}$ of sediment in both 1955 and 1965 , could be expected to overwhelm the human artifice of a narrow, meandering channel. 
Fig. 4. Channel of Cuneo Creek (a) after reconstruction in 1991 (photograph courtesy of the California Department of Parks and Recreation) and (b) in 2000 (photograph by the author, July 2000).
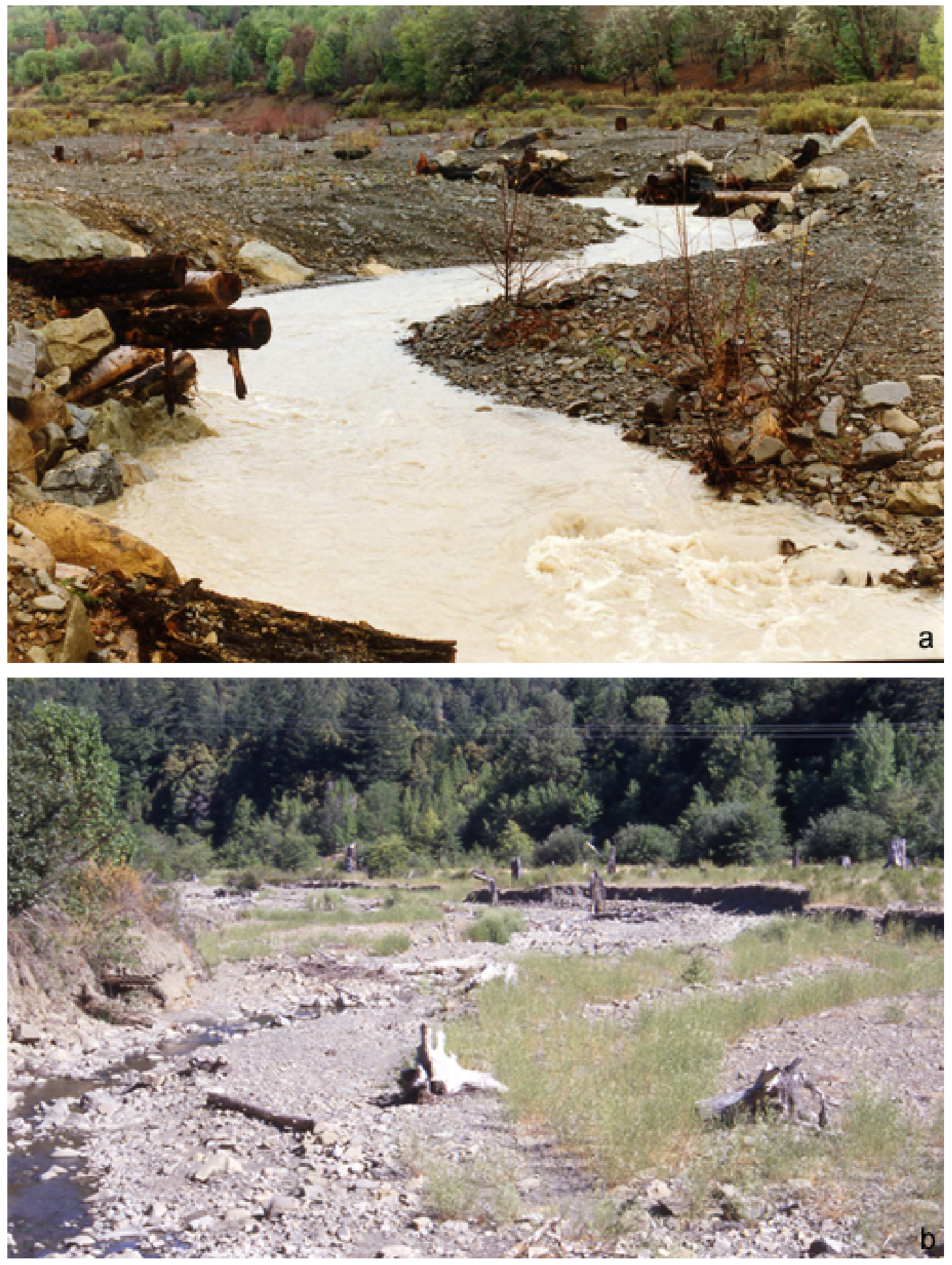
Fig. 5. Design for Cuneo Creek reconstruction project (from Rosgen 1991). The bold, sinuous line is the proposed channel course drawn on a preproject aerial photography base (photography courtesy of the California Department of Parks and Recreation).

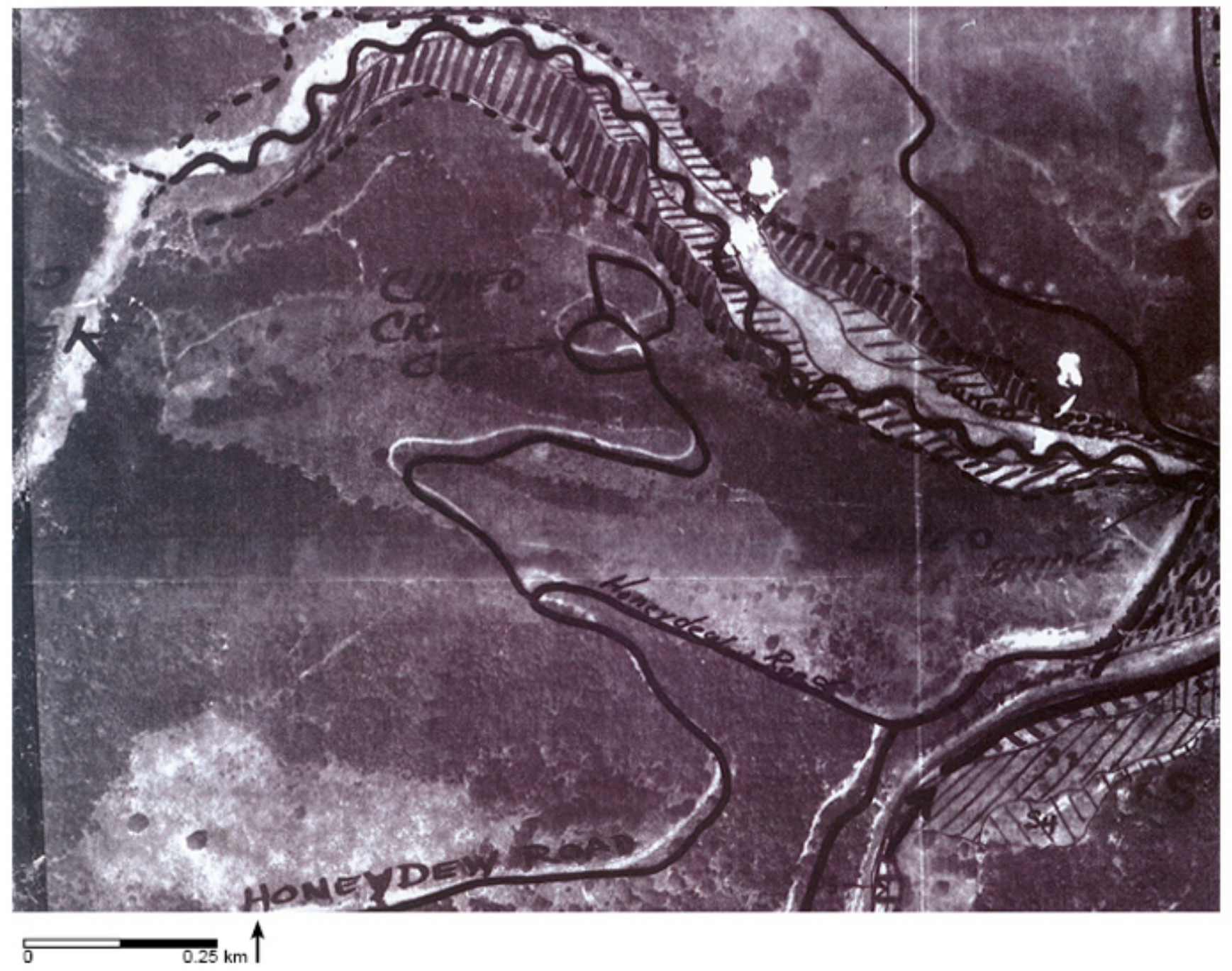

Addendum (11 Jan 2007): Since the mid-1990's California State Parks has embarked on a course of action in the larger Bull Creek catchment primarily addressing upslope sediment sources through removal of, or improvements to, abandoned logging roads and service roads. Parks has already treated approximately $50 \%$ of the roads and is now phasing into upslope and riparian silvicultural treatments to improve forest trajectories toward late seral conditions. Detailed studies and observations over the last decade show that catchment-wide erosion rates, even in the face of historical peak flow highs and major earthquake disturbance, have declined significantly compared to mid-20th century postlogging rates. In concert with the upslope work, State Parks is undertaking a detailed geomorphic and hydrologic analysis of the lower and middle mainstem of Bull Creek to improve floodplain and channel connection, including structure removal or modification. Sediment yields in the Cuneo Creek 
subcatchment of Bull Creek remain high, and thus Parks does not intend any further in-channel projects, but is focusing instead on addressing causes of the disturbance.

\section{Uvas Creek}

Uvas Creek drains the Coast Ranges in California's Santa Clara County and flows into the Pajaro River, which in turn flows into Monterey Bay (Fig. 6). The rapidly urbanizing city of Gilroy lies about $50 \mathrm{~km}$ south of San Jose. When its urban area enveloped Uvas Creek in the early 1990s, the city sought to create a park in the bottomland of Uvas Creek and to improve habitat and passage for steelhead trout (Oncorhynchus mykiss), which migrate up Uvas Creek to spawn in tributaries. At Gilroy, Uvas Creek has a drainage area of $184 \mathrm{~km}^{2}$, a channel slope of about 0.002 , an active channel width of 100-350 m historically, and bed material of sand and gravel. This site was disturbed by instream gravel mining in previous decades. The basin is underlain largely by the highly erodible Franciscan Formation, and these rocks are sheared by faults of the San Andreas system, which runs along the drainage divide. The creek's dynamic flow regime and high supply of coarse sediment would tend to a produce a wide, active, braided channel. Uvas Reservoir, $12 \mathrm{~km}$ upstream, controls runoff from $78 \mathrm{~km}^{2}$, or about $42 \%$ of the drainage area at Gilroy.

The project designers, who were consultants to the city, used the Rosgen approach to determine the following:

"The channel was once a stable C4 channel (Rosgen 1985, ...). C4 channels have welldefined point bars and floodplains, which are used as energy-dissipating features during high-stage, high-energy events. Energy is also dissipated by the sinuous meander pattern (Leopold, Wolman, Miller 1964)[sic]." (Zembsch 1993:2)

Because the application of the classification system predicted that the $\mathrm{C} 4$ form would be stable, the consultants designed a Rosgen C4, i.e., meandering, channel for a 900-m reach, with symmetrical meander bends whose amplitude and wavelength were based on multiples of the consultants' estimated bankfull channel width (Fig. 7). As is typical of such projects, the outside bends were protected by revetments of boulders and root wads, and a series of vortex rock weirs was built along the channel (Fig. 8A). These boulders and root wads are often termed "natural materials" in such projects, even in reaches such as Uvas Creek in which boulders would not naturally occur. The project was constructed in November 1995 and, as seen in Fig. 8B, washed out three months later in February 1996 during a high flow with a return interval of about $6 \mathrm{yr}$ (Kondolf et al. 2001).

Although the restoration plan asserted that the channel was once a stable $\mathrm{C} 4$ channel, it did not present historical evidence to support this assertion. In fact, the available historical sources suggest that the channel was braided in the 19th and early 20th centuries (Kondolf et al. 2001). For example, an 1879 map of the creek shows multiple channels in the project reach from the site of the modern Santa Teresa Road bridge downstream (Fig. 9). Similarly, ground photographs show that the channel had a broad, unvegetated gravel bed in the 1890s, and the earliest available aerial photographs show that the channel was clearly braided in 1939 (Kondolf et al. 2001). Thus, the historical evidence indicates that the channel of Uvas Creek was braided, as is typical of the river channels draining the California Coast Ranges with their episodic flow regime and high sediment loads. Such channels commonly undergo cyclical changes: large floods clear out vegetation and rework the channel, leaving wide unvegetated beds. Subsequent years without large floods permit the recolonization of vegetation and the development of a single-thread channel within a forested corridor, until the next large flood scours the bed and "resets" the channel (Kondolf 1998).

From the perspective of geomorphic theory, there is no obvious reason to expect the channel of Uvas Creek to adopt a stable, single-thread morphology if its flow regime and sediment load, the independent variables that drive channel processes, remain unchanged. One of the consultants who designed the project raised concerns that the channel would not be stable because the final design drawings called for fewer rock weirs and the revetments at the meander bends did not extend as far upstream and downstream as originally specified. However, the geomorphic evidence strongly suggests that the reconstructed channel did not fail because of design details. The revetments and grade controls were not eroded but simply abandoned by the channel as it cut through the constructed floodplain, which, because it was still unvegetated, offered little hydraulic resistance to 
Fig. 6. Location map, Uvas Creek (from Kondolf et al. 2001).

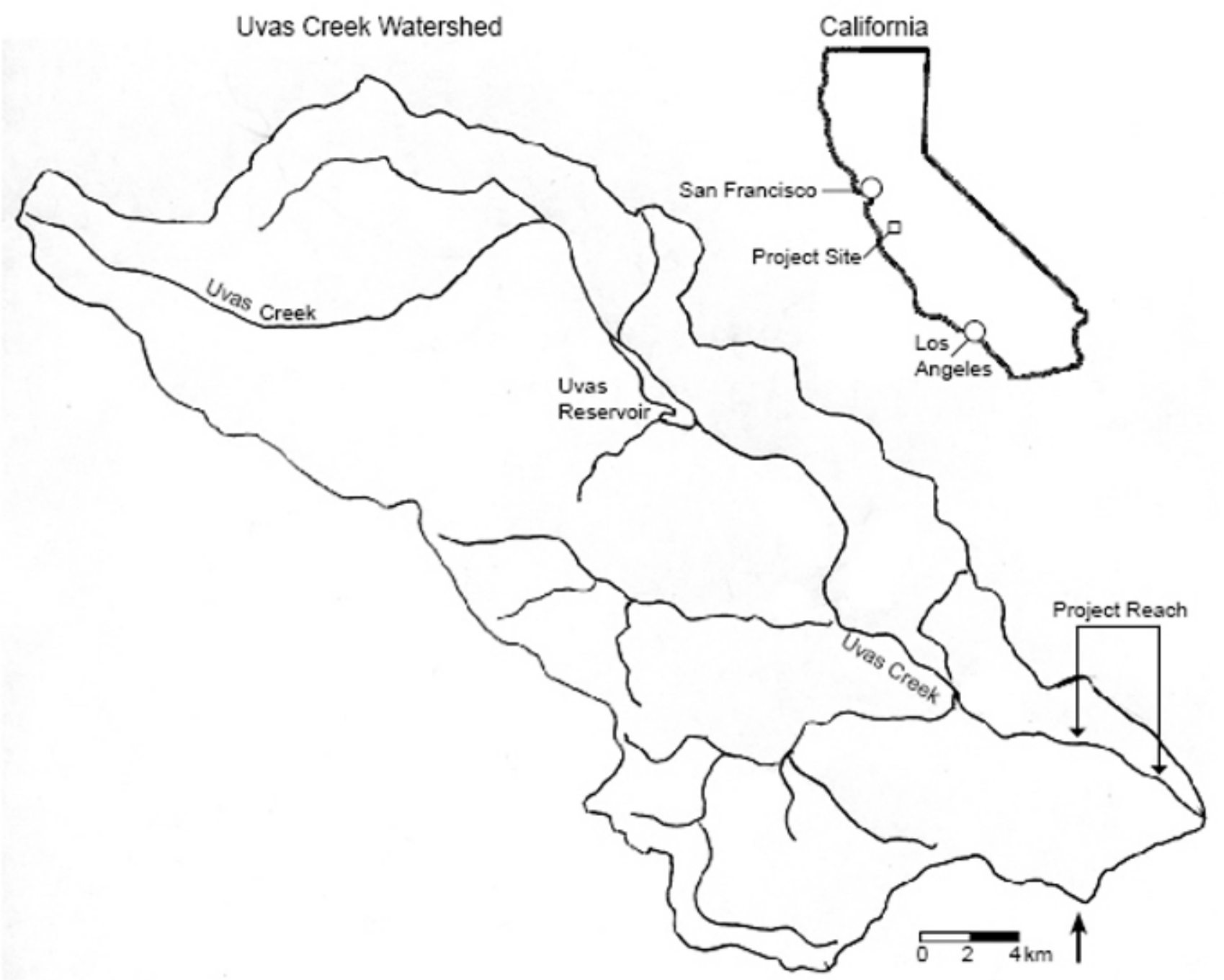

overbank flow. More fundamentally, we must question the concept of imposing an idealized, single-thread, meandering channel on a reach that was historically braided, and which would likely be braided at high flows given its sediment supply.

\section{CONTINUED POPULARITY OF THE APPROACH}

Despite the documented failures of single-thread, meandering channels designed on the basis of the
Rosgen classification system, this approach to channel reconstruction remains popular among government agencies in North America, many of whom require its use by applicants for funding. On the Clark Fork River, Montana, Milltown Dam is slated for removal because it is structurally unsafe and retains deposits of contaminated sediments immediately upstream. The deposits will be excavated, and a rock-lined, trapezoidal channel constructed through the remaining heavily contaminated sediments to isolate them from the active channel. In addition to this necessary 
Fig. 7. Plan for channel reconstruction, Uvas Creek, prepared by consultants (Source: Uvas Creek project files, City of Gilroy, California).

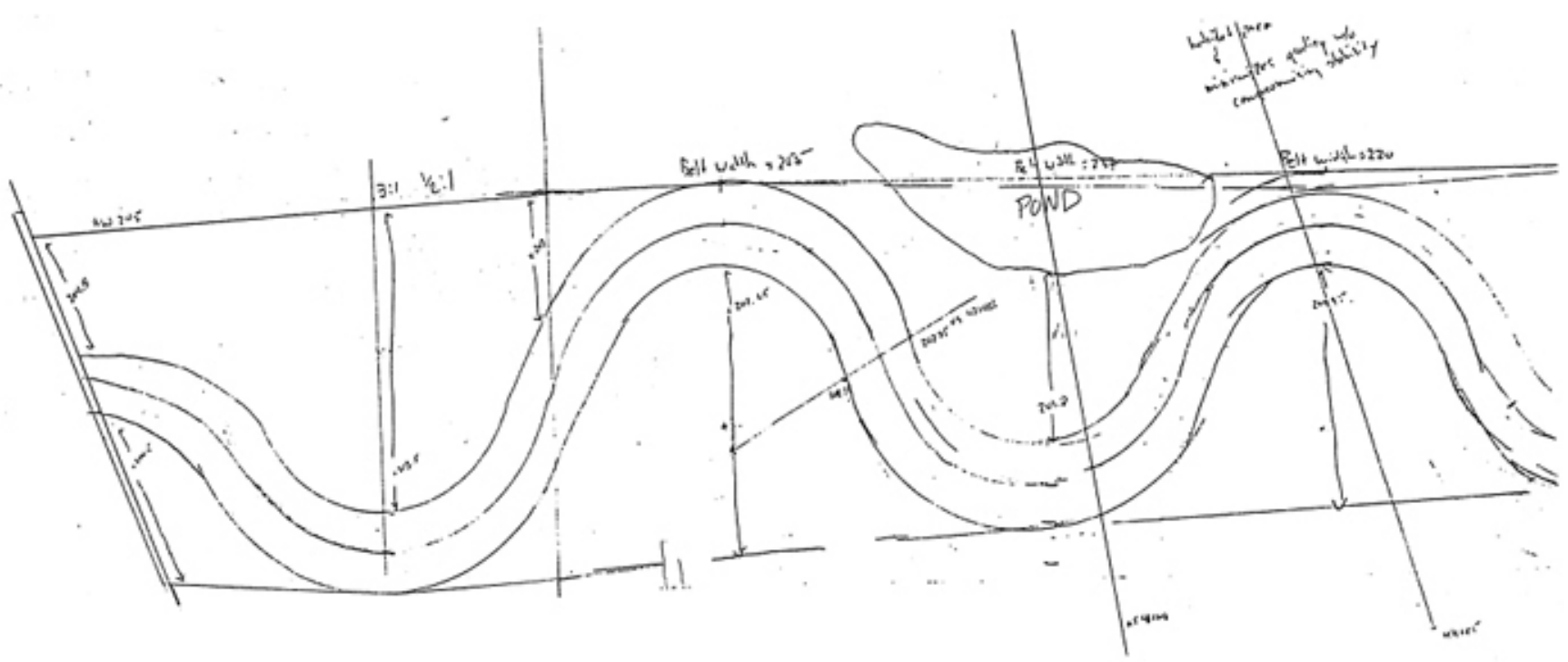

reconstruction, however, the State of Montana has proposed the reconstruction of about $8 \mathrm{~km}$ of the river channel upstream into a single-thread, meandering channel based on the Rosgen classification system (Water Consulting Inc. and Rosgen 2000). However, if we compare the channel design to the historical form as recorded on old topographic maps, there is no evidence that the channel in this reach was a single-thread, meandering channel (Fig. 10).

Why the continued popularity of this approach? Why are river channels so often subjected to reconstruction to a meandering form even when there is nothing demonstrably wrong with them as they are, e.g., Deep Run, Maryland, as described by Smith and Prestegaard (2005), or when historical evidence does not indicate that they were formerly meandering? In many cases, stability is a goal, explicit or implicit, of many restoration projects, not because of any need to protect human infrastructure, but from an implicit assumption that stability is inherently good from an ecological point of view. The Rosgen classification system often predicts that the "proper," and therefore stable, channel form for a given set of variables, e.g., valley slope, grain size, etc., is a meandering channel. The Rosgen approach is typically applied by people without rigorous academic training in fluvial geomorphology, but who have been trained instead in a series of commercially offered short courses 5-8 days in duration.

Besides the popularity of the Rosgen approach and its frequent specification of a meandering channel, there may be another reason that single-thread, meandering channels are so often the goal of channel reconstructions: an unacknowledged cultural preference for stable, meandering channels. This cultural bias may be the true driver of these river restoration decisions, even though the designs are usually presented as scientifically based.

\section{A cultural preference for single-thread, meandering channels?}

The notion that there is a deeply rooted cultural preference for single-thread, meandering channels has its roots in 18th-century English landscape theory. In his classic text, Hogarth (1753) identified the importance of serpentine line in our perception 
Fig. 8. Views downstream from Santa Teresa Boulevard bridge to project reach on Uvas Creek in (A) January 1996, two months after construction, and (B) July 1997, after the project washed out in February 1996. Photograph A courtesy of the City of Gilroy, photograph B by the author.
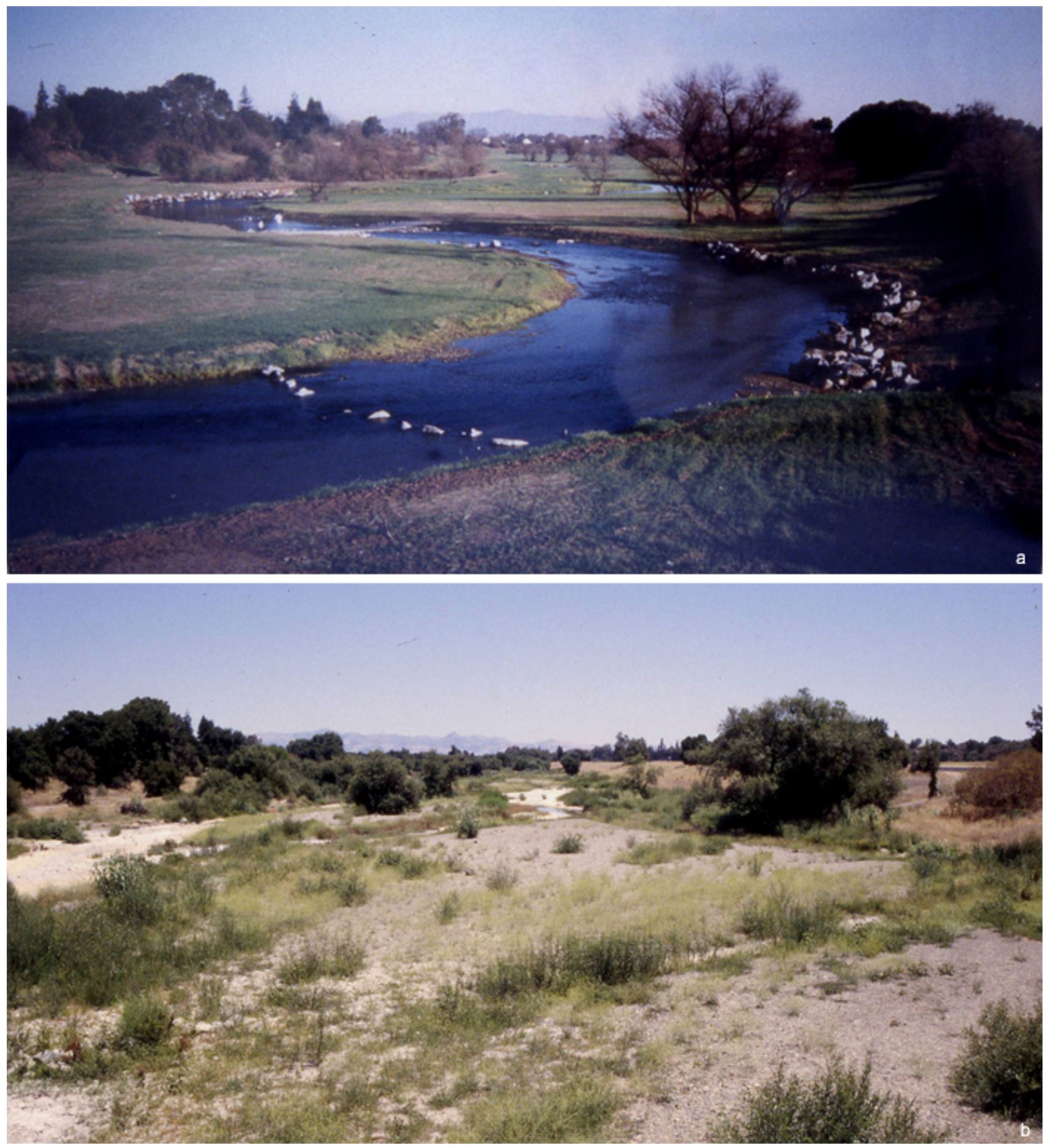
Fig. 9. Detail from the Santa Clara County Atlas of 1876 by Thompson \& Crest (courtesy of the Earth Sciences Map Collection of the University of California at Berkeley).

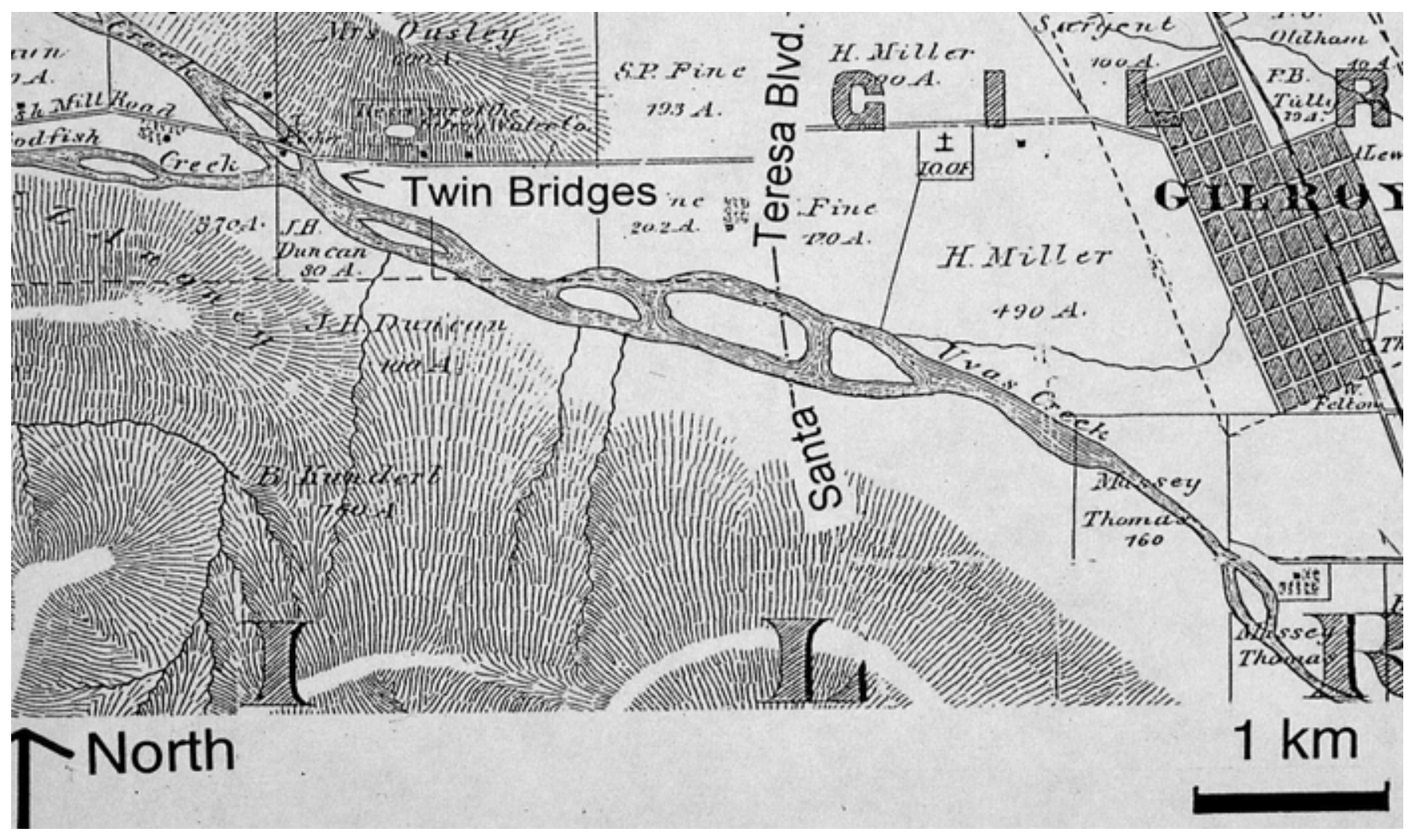

of beauty and as an element that appears in great works of art from classical times as well as landscapes:

\begin{abstract}
"The eye hath this sort of enjoyment in winding walks, and serpentine rivers, and all sorts of objects, whose forms, as we shall see hereafter, are composed principally of what I call waving and serpentine lines ... that leads the eye in a wanton kind of chase, and from the pleasure that gives the mind, entitles it to the name of beautiful."
\end{abstract}

Hogarth argued that the serpentine line provided the greatest aesthetic pleasure, especially when actively moving, an idea echoed in the 19th century by Frederick Law Olmsted in his designs for roads and the experience of the traveler across the landscape (Myers 2004). Thus, the river moving through a serpentine channel has the elements needed for the experience of beauty according to Hogarth's theory. These notions of beauty were put into practice on the English landscape by designers such as Capability Brown, whose extensive practice in the late 18th century included the construction of serpentine channels on the estates of his wealthy clients.

Landscape and psychological research support Hogarth's concept. In his analysis of townscapes, Cullen (1961) found that the anticipation of what lay around the corner made curved streets preferable, a notion more broadly applied by Appleton (1975) to "deflected vistas," including paths, rivers, and valleys. Ulrich (1983) found that such deflected vistas were preferred by and elicited curiosity in subjects. Kaplan and Kaplan (1984) designated this landscape property as "mystery," conveying the opportunity to explore and a promise to learn more with a changing vantage point as one 
moves more deeply into the scene. An advertisement for the Jeep Cherokee sport utility vehicle, which ran widely in magazines and newspapers in North America in 2004 and 2005, featured a sinuously bending highway that transitioned into a sinuously meandering river, a popular manifestation of this cultural preference for these curved lines in road and stream.

A colleague who works for a state agency reported to me her experience visiting the site of another meandering channel reconstruction in northern California shortly after it had washed out. As they stood on the bridge looking upstream at the site where the constructed meander bends had been, the heavy equipment operator who had built the project said, "You should have seen it. It was beautiful."

\section{CONCLUSION}

Just as Capability Brown and his peers were busy constructing serpentine channels on country estates in England in the 18th and 19th centuries, today there is a thriving industry of consulting firms that design and construct meandering trout streams on the ranches of wealthy clients, with six such firms flourishing in Bozeman, Montana, alone.

There is evidence that in our culture we find meander bends to be aesthetically pleasing, and this unstated and generally unrecognized influence may underlie many of the symmetrical meandering channels that are constructed today. The restoration plans may speak of width-to-depth ratios, meanderbend wavelengths, bankfull discharge, and alphanumeric designations of "stream type," but to what degree are designers of these channel reconstructions actually drawn unconsciously to impose a culturally preferred, ideal form on what are inherently "messy ecosystems" (Nassauer 1995)? How much of the seemingly scientific jargon is simply justification for a channel alteration whose real appeal is not even understood by those who fund and build these projects? Why are channels rarely reconstructed to a braided form in North America? Among managers and practitioners, braided channels are widely viewed as pathological and indicative of problem conditions such as too much sediment. However, rivers draining mountainous terrain commonly have a braided form naturally. These braided channels may not constitute the classic, ideal trout stream often sought by restoration designers, but they provide habitat for native species that have evolved with them. In Europe the loss of dynamic, braided channels is mourned, and their restoration has been attempted in Bavaria by removing stabilizing vegetation from banks and bars and by reinstating coarse sediment supply (Binder 2004, 2005).

The preference for stable channels evinced by the restoration projects now typical in North America reflects an implicit assumption that river channels should be stable and that rivers can be restored by physically creating desired channel forms. This approach flies in the face of the scientific understanding that the form and dimensions of alluvial river channels reflect the flow and sediment load supplied to them, and runs contrary to the recognition that, to sustainably restore river ecosystems, the processes that create and maintain river channels should be restored, and that these processes can then create the forms (Kondolf 2000, Wohl et al. 2005, Kondolf et al. 2006)

If ecological restoration is really our goal, why create a single-thread, meandering channel with armored banks, even if armored with "natural materials" like boulders and logs, in rivers that in nature would be dynamically migrating? In the case studies presented here, the single-thread channels promptly washed out, and most observers would agree that the projects failed. However, what if the channels had remained stable, within the idealized course designated by the designers and constrained by the bank armoring? The project would have successfully stabilized the channel, but we can argue that channel stabilization conflicts with the goal of restoring ecological function (Palmer et al. 2005). In other cases, the channel may be unstable because of its geologic setting and catchment history, such that reach-level interventions may result in shortterm habitat improvements but are probably doomed by the ongoing channel instability (Shields et al. 2003).

It is not always possible to permit river channels to migrate, erode, and deposit. In many settings, urban development or other infrastructure can impinge so closely that the channel must be stabilized. However, for the case studies presented here and many other such projects in California, the channels are within parks or other rural settings in which they could migrate without creating conflicts with human resources. The reflexive armoring of the bank to lock the channel in place, in an idealized meandering form, is inconsistent with the restoration of 
ecological process and sustainable restoration of ecosystem function.

As observed by Mozingo (1997), there is a considerable literature documenting negative public reaction to ecologically valuable landscapes. Ecologically, "What is good may not look good, and what looks good may not be good" (Nassauer 1995). We can distinguish tidy landscapes from scruffy landscapes. The former would include the parklike setting of a 19th-century English country estate or a 20th-century American corporate campus, with grazed or mown grass and well spaced trees. However, if we stopped grazing/mowing this landscape and permitted successional processes to begin, the invading vegetation would give the landscape a disorderly appearance, as if no one was taking care of it. The scruffy landscape would have greater wildlife value but would not appeal to the public sense of aesthetics. Thus, Nassauer (1995) argued that patches of native prairie should be set off by neat fences (an orderly frame) as cues that someone is caring for the landscape, that this bit of disorder is deliberate. Applying these ideas to river channels, we can see a strong preference for the tidiness of stable, single-thread channels, even in rivers in which this form is exotic. The heavy equipment operator waxes poetic in describing the beautiful meandering channel he created but does not critically evaluate whether the native species would benefit more from a messy, dynamically changing channel more in keeping with the climate and geology of the California Coast Range.

All this is not to say we should never build meandering channels. There are rivers in which these forms belong, and especially when restoring reaches that have been artificially straightened, the meandering form can provide a variety of habitats, especially if the restored channel is not armored but allowed to migrate. However, the reflex to construct fixed meander bends in virtually every restoration project is clearly not based in sound geomorphic or ecological science. The reigning paradigm of designing a bankfull channel using the Rosgen classification scheme is not a sophisticated approach to the complex task of restoring river ecosystems. As often applied, the technical analyses presented to justify these meandering channel designs can be viewed as but a layer of (pseudo) science over a deep-seated cultural preference. A more thoughtful, nuanced approach to river restoration must be based on an understanding of the geomorphic and ecological contexts, historical changes, and resulting constraints and opportunities (Kondolf and Larson 1995, Frothingham et al. 2003).

Responses to this article can be read online at: http://www.ecologyandsociety.org/voll1/iss2/art42/ responses/

\section{Acknowledgments:}

This paper benefited from the lively interchange and discussion in the relaxed interdisciplinary environment created by the Landscape Ecology Group, Umea University, Sweden, at the Second International Symposium on Riverine Landscapes in Storforsen, Sweden, where this paper was originally presented. It also benefited enormously from stimulating discussions at the symposium and from comments by anonymous peer reviewers. I thank Francine Hughes for her suggestion of the terms "tidy" and "scruffy" for landscapes, John Moore for developing the map superimposing the proposed Clark Fork channel reconstruction onto the 1907 topographic map, Bill Headley and staff at the City of Gilroy for sharing photographs and other documents related to the Uvas Creek Project, and the California Department of Parks and Recreation for sharing Cuneo Creek project documents and data.

\section{LITERATURE CITED}

Appleton, J. 1975. The experience of landscape. John Wiley, London, UK.

Bernhardt, E. S., M. A. Palmer, J. D. Allan, G. Alexander, K. Barnas, S. Brooks, J. Carr, S. Clayton, C. Dahm, J. Follstad-Shah, D. Galat, S. Gloss, P. Goodwin, D. Hart, B. Hassett, R. Jenkinson, S. Katz, G. M. Kondolf, P. S. Lake, R. Lave, J. L. Meyer, and T. K. O'Don. 2005.

Synthesizing U.S. river restoration efforts. Science 308:636-637.

Binder, W. 2004. Restoration of rivers and floodplains in Bavaria. Pages 27-32 in D. Geres, editor. River Restoration 2004: principles, processes, practices; proceedings of the Third ECRR Conference on River Restoration 2004 
(Zagreb, 2004). European Centre for River Restoration, National Environmental Research Centre, Roskilde, Denmark.

Binder, W. 2005. The rehabilitation of the Isar in Munich: a channelized river back to nature. Pages 290-295 in J. T. Toubier and J. Schanze, editors. Urban river rehabilitation: proceedings of the International Conference on Urban River

Rehabilitation (Dresden, 2005). Leibnitz Institute of Ecological and Regional Development, Dresden, Germany.

Brautigan, R. 1967. Trout fishing in America. Laurel, New York, New York, USA.

Brookes, A. 1987. Restoring the sinuousity of artificially straightened stream channels. Environmental Geology and Water Science 10:33-41.

Burnson, D. 1992. Lower Cuneo channel dimensions report of findings. California Department of Parks and Recreation, Sacramento, California, USA.

Cullen, G. 1961. Townscapes. Architectural Press, London, UK.

Downs, P. W., K. S. Skinner, and G. M.

Kondolf. 2001. Rivers and streams. Pages 267-291 in M. R. Perrow and A. J. Davy, editors. Handbook of ecological restoration: principles of

restoration. Cambridge University Press, Cambridge, UK.

Doyle, M. W., D. E. Miller, and J. M. Harbor. 1999. Should river restoration be based on classification schemes or process models? Inisights from the history of geomorphology. Available online at: http://www.blwi.com/DoyleMD StreamR estoration Historical 1999aa.pdf.

Frothingham, K. M., B. L. Rhoads, and E. E. Herricks. 2003. A multiscale conceptual framework for integrated ecogeomorphological research to support stream naturalization in the agricultural midwest. Environmental Management 29:16-33.

Gasith, A., and V. H. Resh. 1999. Streams in Mediterranean-climate regions: abiotic influences and biotic responses to predictable seasonal events. Annual Review of Ecology and Systematics 30:51-81.
Goldi, C. 1989. Resuscitation programme for flowing waters in the Canton of Zurich. Anthos 2:1-5.

Gunderson, L. H., and C. S. Holling. 2002. Panarchy: understanding transformations in human and natural systems. Island Press, Washington, D. C., USA.

Hansen, A. 2003. Post-project appraisal of a channel reconstruction on Cuneo Creek, California. Available online at: http://repositories.c dlib.org/wrca/restoration/.

Hecht, B. 1994. South of the spotted owl: restoration strategies for episodic channels and riparian corridors in central California. Pages 104-117 in D. M. Kent and J. T. Zentner, editors. Western wetlands: selected proceedings of the 1993 Conference of the Society of Wetland Scientists.

Society of Wetland Scientists, McLean, Virginia, USA.

Hogarth, W. 1753. The analysis of beauty.

Reprinted in 1997 by Yale University Press, New Haven, Connecticut, USA.

Iversen, T. M., B. Kronvang, B. L. Madsen, P. Markmann, and M. B. Nielsen. 1993. Reestablishment of Danish streams: restoration and maintenance measures. Aquatic Conservations: Marine and Freshwater Ecosystems 3:73-92.

Juracek, K. E., and F. A. Fitzpatrick. 2003. Limitations and implications of stream classification. Journal of the American Water Resources Association 39:659-670.

Kaplan, R., and S. Kaplan. 1989. The experience of nature: a psychological perspective. Cambridge University Press, New York, New York, USA.

Kondolf, G. M. 1995a. Five elements for effective evaluation of stream restoration. Restoration Ecology 3(2):133-136.

Kondolf, G. M. 1995b. Geomorphological stream channel classification in aquatic habitat restoration: uses and limitations. Aquatic Conservation 5:127-141.

Kondolf, G. M. 1998. Lessons learned from river restoration projects in California. Aquatic 
Conservation 8:39-52

Kondolf, G. M. 2000. Process vs form in restoration of rivers and streams. Pages 120-124 in D. L. Scheu, editor. Annual meeting proceedings of the American Society of Landscape Architects (St. Louis, 2000). American Society of Landscape Architects, Washington, D.C., USA.

Kondolf, G. M., A. Boulton, S. O'Daniel, G. Poole, F. Rahel, E. Stanley, E. Wohl, A. Bang, J. Carlstrom, C. Cristoni, H. Huber, S. Koljonen, P. Louhi, and K. Nakamura. 2006. Process-based ecological river restoration: visualizing threedimensional connectivity and dynamic vectors to recover lost linkages. Ecology and Society 11(2): 5. [online] URL: http://www.ecologyandsociety.org/ vol11/iss 2/art5/.

Kondolf, G. M., and M. Larson. 1995. Historical channel analysis and its application to riparian and aquatic habitat restoration. Aquatic Conservation 5:109-126.

Kondolf, G. M., and E. M. Micheli. 1995. Evaluating stream restoration projects. Environmental Management 19:1-15.

Kondolf, G. M., H. Piégay, and N. Landon. 2002. Channel response to increased and decreased bedload supply from land-use change: contrasts between two catchments. Geomorphology 45:35-51.

Kondolf, G. M., M. W. Smeltzer, and S.

Railsback. 2001. Design and performance of a channel reconstruction project in a coastal California gravel-bed stream. Environmental Management 28(6):761-776.

Leopold, L. B., M. G. Wolman, and J. P. Miller. 1964. Fluvial processes in geomorphology. W. H. Freeman, San Francisco, California, USA.

Malakoff, D. 2004. The river doctor. Science 305:937-939.

Miller, J. R., and J. B. Ritter 1996. An examination of the Rosgen classification of natural rivers. Catena 27:295-299.

Mozingo, L. A. 1997. The aesthetics of ecological design: seeing science as culture. Landcape Journal 16:46-59.
Myers, M. E. 2004. The line of grace: principles of road aesthetics in the design of the Blue Ridge Parkway. Landscape Journal 23:121-140.

Nassauer, J. I. 1995. Messy ecosystems, orderly frames. Landscape Journal 14:161-170.

National Research Council (NRC). 1992.

Restoration of aquatic ecosystems. National Academy Press, Washington, D.C., USA.

Palmer, M. A., E. S. Bernhardt, J. D. Allan, P. S. Lake, G. Alexander, S. Brooks, J. Carr, S. Clayton, C. Dahm, J. Follstad Shah, D. L. Galat, S. Gloss, P. Goodwin, D. H. Hart, B. Hassett, R. Jenkinson, G. M. Kondolf, R. Lave, J. L. Meyer, T.K. O'Donnell, L. Pagano, P. Srivastava, and E. Sudduth. 2005. Standards for ecologically successful river restoration. Journal of Applied Ecology 42:208-217.

Richards, K. S., J. Brasington, and F. Hughes. 2002. Geomorphic dynamics of floodplains: ecological implications and a potential modelling strategy. Freshwater Biology 47:559-579.

Rosgen, D. L. 1985. A stream classification system. Pages 91-95 in U.S. Forest Service, Rocky Mountain Forest and Range Experiment Station. Riparian ecosystems and their management. First North American Riparian Conference. U.S Forest Service Report RM-120.

Rosgen, D. L. 1991. Bull Creek Watershed restoration plan. Wildland Hydrology, Pagosa Springs, Colorado, USA.

Rosgen, D. L. 1994. A classification of natural rivers. Catena 22:169-199.

Rosgen, D. L. 1996. Applied river morphology. Wildland Hydrology, Pagosa Springs, Colorado, USA.

Rosgen, D. L., and B. L. Fittante. 1986. Fish habitat structures: a selection guide using stream classification. Pages 163-179 in J. G. Miller, J. A. Arway, and R. F. Carline, editors. Proceedings of the 5th Trout Stream Improvement Workshop (Lock Haven, 1986). Pennsylvania Fish Commission Publications, Harrisburg, Pennsylvania, USA.

Shields, F. D., S. S. Knight, N. Morin, and J. 
Blank. 2003. Response of fishes and aquatic habitats to sand-bed stream restoration using large woody debris. Hydrobiologia 494:251-257.

Short, D. A. 1993. A sediment budget for a small northcoast drainage basin, Humboldt county, California. Thesis. Humboldt State University, Arcata, California, USA.

Smith, S. M., and K. L. Prestegaard. 2005.

Hydraulic performance of a morphology-based stream channel design. Water Resources Research 41: doi: 10.1029/2004WR003926.

Ulrich, R. S. 1983. Aesthetic and effective response to natural environment. Pages 85-125 in I. Altman and J. Wohlwill, editors. Behavior and the natural environment. Plenum, New York, New York, USA.

Ward, J. V., and J. A. Stanford. 1995. Ecological connectivity in alluvial river ecosystems and its disruption by flow regulation. Regulated Rivers Research and Management 11:105-119.

Water Consulting Inc. and D. Rosgen. 2002.

Draft conceptual restoration plan for the Clark Fork River and Blackfoot River near Milltown Dam; report to State of Montana, Natural Resources Damage Program and Department of Fish, Wildlife and Parks. Water Consulting Inc., Hamilton, Montana, USA, and Wildland Hydrology, Fort Collins, Colorado, USA.

Wohl, E., P. L. Angermeier, B. Bledsoe, G. M. Kondolf, L. MacDonnell, D. M. Merritt, M. A. Palmer, N. L. Poff, and D. Tarboton. 2005. River restoration. Available online at: http://www.cuahsi. org/cyberseminars/Wohl-20040923-paper.pdf.

Wolman, M. G., and R. Gerson. 1978. Relative scales of time and effectiveness of climate in watershed geomorphology. Earth Surface Processes 3:189-209.

Zembsch, S. 1993. Uvas Creek Preserve creek restoration plan; report to the Habitat Restoration Group and Beals Landscape Architects by Watershed Science, Aromas, California. Watershed Science, Aromas, California, USA. 